\title{
Event-Related Potentials Elicited by Errors during the Stop-Signal Task. I. Macaque Monkeys
}

\author{
David C. Godlove, Erik E. Emeric, Courtney M. Segovis, Michelle S. Young, Jeffrey D. Schall, and Geoffrey F. Woodman \\ Department of Psychology, Vanderbilt Vision Research Center, Center for Integrative and Cognitive Neuroscience, Vanderbilt Brain Institute, Vanderbilt \\ University, Nashville, Tennessee 37240
}

The error-related negativity (ERN) and positivity (Pe) are components of event-related potential (ERP) waveforms recorded from humans and are thought to reflect performance monitoring. Error-related signals have also been found in single-neuron responses and local-field potentials recorded in supplementary eye field and anterior cingulate cortex of macaque monkeys. However, the homology of these neural signals across species remains controversial. Here, we show that monkeys exhibit ERN and Pe components when they commit errors during a saccadic stop-signal task. The voltage distributions and current densities of these components were similar to those found in humans performing the same task. Subsequent analyses show that neither stimulus- nor response-related artifacts accounted for the error-ERPs. This demonstration of macaque homologues of the ERN and Pe forms a keystone in the bridge linking human and nonhuman primate studies on the neural basis of performance monitoring.

\section{Introduction}

To thrive, organisms must detect when their responses fail to meet expectations through performance monitoring. Researchers investigating performance monitoring in humans have made inferences based on event-related potentials (ERPs) or neuroimaging methods, whereas investigators using monkeys have relied on intracranial recordings (for review, see Paus, 2001; Ridderinkhof et al., 2004; Schall and Boucher, 2007; Taylor et al., 2007; Hikosaka and Isoda, 2010; Passingham et al., 2010). The present work addresses this fundamental question: Is the monkey executive control system a valid model of human performance monitoring?

The first electrophysiological correlate of performance monitoring discovered in humans, the error-related negativity (ERN, also known as the Ne), was independently reported by Falkenstein et al. (1990) and Gehring et al. (1993). The ERN has a frontocentral scalp distribution and peaks $\sim 50-100 \mathrm{~ms}$ following incorrect manual responses (for review, see Gehring et al., 2011). Several groups have observed the ERN during the stop-signal task (also known as the countermanding task), which is used to investigate behavioral inhibition and execu-

Received June 30, 2011; revised Aug. 13, 2011; accepted Sept. 7, 2011.

Author contributions: D.C.G., J.D.S., and G.F.W. designed research; D.C.G., E.E.E., and C.M.S. performed research; D.C.G., E.E.E., J.D.S., and G.F.W. contributed unpublished reagents/analytic tools; D.C.G. and M.S.Y. analyzed data; D.C.G., J.D.S., and G.F.W. wrote the paper.

This work was supported by NIH Grants R01-MH55806, R01-EY019882, P30-EY08126, and P30-HD015052 and by Robin and Richard Patton through the E. Bronson Ingram Chair in Neuroscience. We thank R. Reinhart and J. Haitas for help with data analysis. G. Logan, D. Zald, R. Heitz, and B. Purcell provided useful comments on the manuscript. M. Feurtado, A. Garr, and C. Suell helped with animal care.

The authors report no conflicts of interest.

Correspondence should be addressed to either Dr. Geoffrey F. Woodman or Dr. Jeffrey D. Schall, Department of Psychology, PMB 407817, 2301 Vanderbilt Place, Vanderbilt University, Nashville, TN 37240-7817. E-mail: geoffrey.f.woodman@vanderbilt.edu or jeffrey.d.schall@vanderbilt.edu.

DOI:10.1523/JNEUROSCI.3349-11.2011

Copyright $\odot 2011$ the authors $\quad 0270-6474 / 11 / 3115640-10 \$ 15.00 / 0$ tive control (Endrass et al., 2005; Liotti et al., 2005; van Boxtel et al., 2005; Krämer et al., 2007; Stahl and Gibbons, 2007; Vocat et al., 2008). Although the ERN is clearly associated with error commission, a variety of hypotheses concerning its relation to cognitive processes have been proposed (Gehring et al., 1993; Falkenstein et al., 2000; Holroyd and Coles, 2002; Luu et al., 2003; Yeung et al., 2004; Brown and Braver, 2005). A number of these theories make specific predictions concerning the anatomical, neurophysiological, and neurochemical mechanisms of the ERN. However, these theories have proven difficult to distinguish using behavioral and imaging data from humans. Animal models of error-ERPs can provide leverage to distinguish between alternative hypotheses of performance monitoring.

However, some have proposed that macaque monkeys do not have the neural substrates necessary to generate performancemonitoring ERPs similar to those observed in humans (Cole et al., 2009, 2010; but see Schall and Emeric, 2010). The argument is based on cytoarchitectural differences in medial frontal cortex between species, as well as perceived differences in the signals observed in human and monkey medial frontal cortex. The presence or absence of an ERN in monkeys would therefore shed light on an important, unresolved issue.

We recorded ERPs from monkeys while they performed the saccade stop-signal task. On trials without stop-signals (no-stop trials), monkeys made saccades to peripheral targets. These correct responses were rewarded. On trials containing stop-signals (stop trials), monkeys often made saccades to targets. These errant responses were not rewarded. Thus, saccades led to either correct responses or errors. By contrasting response-aligned ERPs from these two trial types, we demonstrate the first evidence of error-ERPs in nonhuman primates.

Parts of this paper have been published previously in a conference presentation (Garr et al., 2008). 
Table 1. Implanted electrode locations

\begin{tabular}{|c|c|c|c|c|}
\hline \multirow[b]{2}{*}{ Electrode } & \multicolumn{2}{|c|}{ Monkey F } & \multicolumn{2}{|c|}{ Monkey Y } \\
\hline & $A P$ & $M L$ & AP & $M L$ \\
\hline $\mathrm{Fpz}$ & - & - & 5.33 & 0 \\
\hline $\mathrm{FpFz}$ & - & - & 4.3 & 0 \\
\hline Fp1 & - & - & 4.12 & -1.75 \\
\hline $\mathrm{Fp} 2$ & - & - & 4.12 & 1.63 \\
\hline $\mathrm{Fz}$ & 4.1 & 0 & 3.28 & 0 \\
\hline F1 & 2.7 & -1.4 & - & - \\
\hline $\mathrm{F} 2$ & 2.7 & 1.4 & - & - \\
\hline F3 & - & - & 2.69 & -1.59 \\
\hline F4 & - & - & 2.69 & 1.49 \\
\hline $\mathrm{FCz}$ & - & - & 2.24 & 0 \\
\hline $\mathrm{Cz}$ & - & - & 1.23 & 0 \\
\hline P3 & - & - & -0.61 & -2.19 \\
\hline P4 & - & - & -0.61 & 2.19 \\
\hline $\mathrm{Pz}$ & - & - & -1.75 & 0 \\
\hline $\mathrm{POz}$ & - & - & -2.5 & 0 \\
\hline 01 & -2.1 & -1.4 & -2.81 & -1.64 \\
\hline 02 & -2.1 & 1.4 & -2.81 & 1.54 \\
\hline $\mathrm{Oz}$ & -2.5 & 0 & -3.58 & 0 \\
\hline
\end{tabular}

Stereotaxic locations of implanted electrodes (in $\mathrm{cm}$ ) relative to interaural zero. Electrode names refer to homologous human electrode locations from the international 10-20 placement system. AP, Anterior to posterior; ML, medial to lateral.

\section{Materials and Methods}

Animal care. Data were collected from one male bonnet macaque (Macaca radiata, $\sim 8.5 \mathrm{~kg}$ ) and one female rhesus macaque (Macaca mulatta, $\sim 7 \mathrm{~kg}$ ). Both animals were cared for in accordance with policies set forth by the USDA and Public Health Service Policy on Humane Care and Use of Laboratory Animals and all procedures were performed with supervision and approval from the Vanderbilt Institutional Animal Care and Use Committee.

Surgical details have been described previously (Godlove et al., 2011). Most critically, solid gold surface electrodes, Teflon-coated stainless steel wires, and plastic connectors were constructed and implanted following the method of Woodman et al. (2007). Implanted electrode locations are provided in Table 1.

Stimuli and task. Stimulus presentation, task contingencies related to eye position, and delivery of liquid reinforcement were all under computer control in real time (TEMPO; Reflective Computing). Behavior and electrophysiological signals were recorded during the saccadic stopsignal (countermanding) task (Fig. 1). Stimulus properties and task timing have been reported in detail previously (Godlove et al., 2011). Additional details about the behavioral training regime and task have also been previously described (Hanes and Schall, 1995; Hanes et al., 1998).

Trials were initiated when monkeys fixated a centrally presented square. After a variable time, the central fixation point was extinguished and a target simultaneously appeared at $10^{\circ}$ to the left or right of fixation. On no-stop trials (Fig. 1, top), no further visual stimuli were presented. Monkeys were required to make saccades to targets and hold gaze for 600 ms to obtain reward. On stop trials (Fig. 1, bottom), the fixation point was reilluminated after a variable delay, providing a stop-signal. To obtain reward on stop trials, monkeys withheld eye movements and maintained fixation for a minimum of $1800 \mathrm{~ms}$. These trials were designated as canceled. If monkeys were unable to inhibit the movement, a $1500 \mathrm{~ms}$ timeout was added to the normal intertrial interval of $200 \mathrm{~ms}$, no rewards were given, and the trial was termed noncanceled. Thus, identical responses could be either correct or errant depending on trial context.

An initial set of stop-signal delays (SSDs) from 0 to $420 \mathrm{~ms}$ and separated by either 40 or $60 \mathrm{~ms}$ steps was selected for each recording session. We then manipulated SSD using an adaptive, stair-casing algorithm, which adjusted stopping difficulty based on performance. Stop trials made up $30-40 \%$ of all trials in a given session, with a typical session consisting of several thousand trials. Saccade initiation and termination were detected off-line using a custom algorithm that first detected instantaneous velocity elevated $>30 \%$ s and then calculated the beginning and
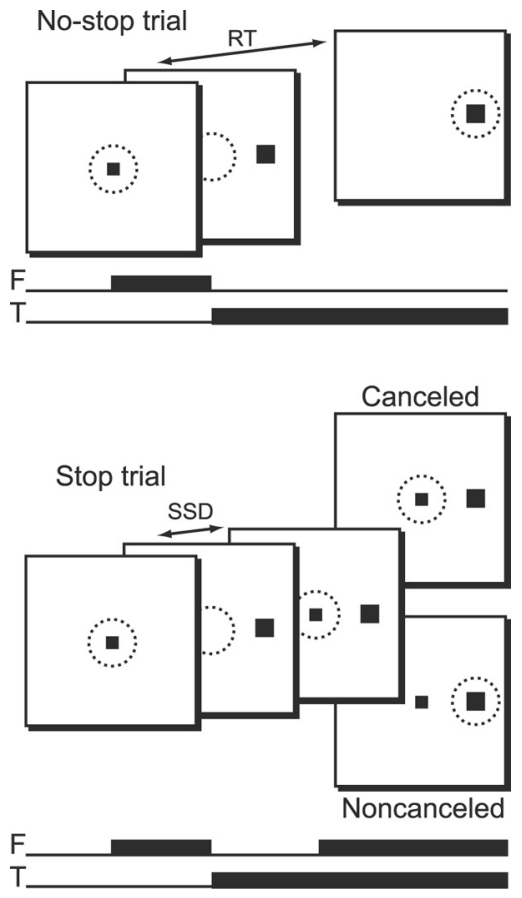

Figure 1. Schematic representation of the saccadic stop-signal (or countermanding) task Top, No-stop trials were initiated when monkeys fixated a centrally presented fixation point. After a variable time, the fixation point was extinguished and a peripheral target was presented simultaneously at one of two possible locations. Monkeys were required to fixate targets with quick saccades for juice rewards. Bottom, Stop trials were initiated in the same way. After a variable time (SSD), the fixation point was reilluminated, instructing the monkeys to withhold movement. Successful inhibition of saccades resulted in rewarded canceled trials, but erran saccades resulted in unrewarded noncanceled trials. Black squares indicate stimulus locations; dotted circles represent area of fixation. F, Fixation point; T, target.

ending of the monotonic change in eye position. We adopted the procedures of Logan and Cowan (1984) implemented by Hanes et al. (1998) to estimate stop signal reaction time (SSRT). In brief, we estimated SSRT using one method that assumes that SSRT is a constant, and another method that assumes that SSRT is a random variable. Since there is no reason to assume an advantage of either of these methods, we averaged the two estimates together to obtain final SSRT measures.

Data acquisition. Eye position was monitored using an infrared eyetracking system (Applied Science Laboratories). Implanted EEG surface electrodes were referenced to linked ears using ear-clip electrodes (Electro-Cap International). All electrode impedances were $<10 \mathrm{k} \Omega$. The EEG from each electrode was amplified with a high-input impedance head stage (Plexon) and bandpass filtered between 0.7 and $170 \mathrm{~Hz}$.

ERP analyses. ERPs were time-locked to saccade initiation or stopsignal onset. Waveforms were baseline corrected during the interval from 150 to $50 \mathrm{~ms}$ before these events. Stop trials on which subjects responded before stop-signal presentation (monkey F, 37\%; monkey Y, 49\%) were not included in error-ERPs since subjects did not have the necessary information to deduce that an error had been committed at time of response. When constructing grand averages collapsed across left and right target locations, the number of trials presented at each location was matched in a given condition by excluding random trials from one target (monkey F, 26\%; monkey Y, 18\%). Trials with voltage deflections greater than $\pm 300 \mu \mathrm{V}$ and trials with amplifier saturation were also excluded from analysis (monkey F, 3\%; monkey Y, 1\%). Single-trial EEG signals were truncated $50 \mathrm{~ms}$ before the onset of the second, non-task-related saccade to eliminate artifacts arising from temporally smeared secondsaccade activity (Godlove, 2010).

Significant ERP differences were assessed using the method of Emeric et al. (2008). This method tests for differences between error and correct ERPs using a thresholding approach similar to those often used in singleunit studies measuring activity onsets in spike-density functions. First, a 
difference wave was calculated by subtracting noncanceled error-ERPs from no-stop correct ERPs. Negative difference wave values indicated that error-ERPs were more negative than correct ERPs, while positive difference wave values indicated an opposite polarity effect. Difference wave values near zero indicated that error and correct ERPs did not differ. Thus, to test for significant differences between error and correct ERPs, we simply observed periods when the difference wave deviated from zero (i.e., baseline) by values larger than those expected by chance.

The intrinsic variability of the difference wave was assessed by calculating the standard deviation across time during the baseline period. This provided a measure of chance fluctuations between error and correct ERPs. Significant epochs were defined as periods when the difference wave deviated from baseline by $>2$ SDs for longer than $50 \mathrm{~ms}$, provided it exceeded 3 SDs in that interval. For presentation, the grand average ERP collapsed across both monkeys was digitally filtered with a zero phase shift $35 \mathrm{~Hz}$ low-pass hamming window ( $\mathrm{SD}=6 \mathrm{~ms}$ ). Unfiltered ERPs are presented individually for each monkey, and all statistical analyses were performed on the unfiltered data.

Current density estimation. MRIs were acquired with a Philips Intera Achieva 3 tesla scanner using SENSE Flex-S surface coils placed above and below the head. T1-weighted gradient-echo structural images were obtained with a $3 \mathrm{D}$ turbo field echo anatomical sequence $(\mathrm{TR}=8.729$ $\mathrm{ms} ; 130$ slices, $0.70 \mathrm{~mm}$ thickness). Segmentations of skin, skull, and brain were performed in CURRY 6 (Compumedics Neuroscan). The cranial surface electrode locations were coregistered to the head model guided by stereotaxic coordinates recorded during surgery. From this 3D head model, a three-compartment Boundary Element Method volume conductor geometry was generated.

Source estimation used ERP difference waves (noncanceled error minus no-stop correct) at time windows of $\pm 30 \mathrm{~ms}$ (ERN) and $\pm 40 \mathrm{~ms}$ [positivity $(\mathrm{Pe})$ ] centered on the peak amplitude of the difference wave from electrodes showing maximal ERN and Pe. Current density was estimated using the sLORETA-weighted accurate minimum norm method (SWARM) (Wagner et al., 2007). SWARM combines the methods of diagonally weighted minimum norm least squares (Dale and Sereno, 1993) and sLORETA (Pascual-Marqui, 2002) to compute a current density vector field with low localization error (Wagner et al., 2007).

Tests for behavioral adjustments. For all analyses of behavioral adjustments related to error-ERPs, data were collected from electrodes that displayed maximum error-related amplitude differences, and data were drawn from the same windows used in current density analysis. We used two methods to test for relationships between error-ERPs and posterror reaction time (RT) adjustments. The first method relied on single-trial amplitude measures. We identified errant noncanceled trials (trial $n$ ), which were followed by no-stop trials (trial $n+1)$. We measured the maximum negative and positive deflections during ERN and Pe windows on trial $n$, and then determined posterror RT adjustments defined as $\Delta \mathrm{RT}$ (RT on trial $n+1$ minus RT on trial $n$ ). We measured the correlation coefficient $(\rho)$ values for maximum ERN/Pe amplitude versus $\Delta \mathrm{RT}$ and subjected these distributions of $\rho$ values to one-sample $t$ tests. This allowed us to determine whether correlations tended to deviate from zero across the entire dataset. For our second method, we first calculated median $\Delta$ RT separately for each monkey. We then constructed two ERPs aligned to the errant saccade on trial $n$ based on a median split of $\Delta \mathrm{RT}$ and tested for significant differences using two-sample $t$ tests. To account for the effects of nonstationarity on RT estimates, we repeated both of these analyses using the correction suggested by Nelson et al. (2010). For this correction, $\Delta \mathrm{RT}$ was calculated as RT on trial $n+1$ minus RT on trial $n-1$. Since similar findings were obtained using both $\Delta$ RT measures, only data from the first $\Delta \mathrm{RT}$ analyses are reported.

Tests for conflict. We also tested for relationships between the amplitude of the ERP negativity around SSRT and neural response conflict. We first normalized the raw EEG traces by $z$-scoring them to remove incidental intersubject and interelectrode amplitude differences. We then identified successfully canceled trials at each SSD. According to findings from Hanes et al. (1998) and Paré and Hanes (2003), canceled trials are those containing the largest magnitude of neural response conflict in the saccadic stop-signal task (see also Stuphorn et al., 2000). We identified no-stop trials from each session with RTs $>$ SSD + SSRT. These latency-
Table 2. Summary statistics for stop-signal task performance

\begin{tabular}{lllll}
\hline & No-stop RT & Noncanceled RT & $p$ (Noncanceled) & SSRT \\
\hline Monkey F & $285 \pm 77$ & $250 \pm 75$ & 0.54 & 94 \\
Monkey Y & $252 \pm 87$ & $218 \pm 92$ & 0.53 & 71 \\
\hline
\end{tabular}

Reaction times ( \pm 1 SD), probability of committing errant noncanceled saccades, and SSRTs for each subject collapsed across sessions.

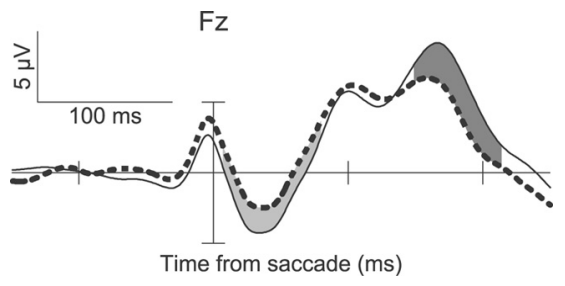

Figure 2. Monkey ERPs showing the ERN and Pe when errors are committed in the saccadic stop-signal task relative to correct trials with the same behavior. Response-aligned ERPs from correct no-stop trials (thin solid line) and errant noncanceled trials (thick dashed line) are displayed. ERPs are collapsed across monkeys. On error trials, a significant negativity can be observed beginning $8 \mathrm{~ms}$ after the response and ending $81 \mathrm{~ms}$ after the response (light gray). A later positivity can also be observed $150-215 \mathrm{~ms}$ after the errant response (dark gray).

matched trials are those that were slow enough to have been successfully canceled had stop-signals been presented, providing an appropriate control for canceled trials (Hanes et al., 1998; Godlove et al., 2011). We then constructed ERPs from canceled and no-stop trials at each SSD and measured mean amplitude on canceled trials and latency matched nostop trials in the window $-50-+100 \mathrm{~ms}$ around SSRT. This window corresponds to the time of conflict-related neural modulation in the supplementary eye field (SEF) (Stuphorn et al., 2000; Emeric et al., 2010). By subtracting mean no-stop voltage from mean canceled voltage, we obtained measurements of the amplitude of the canceled-trial negativity. Finally, we tested to see whether the amplitude of canceled-trial negativity was related to response conflict by assessing its correlation with SSD and the probability of committing an errant saccade.

\section{Results}

\section{Behavior}

Behavioral results are summarized for each monkey in Table 2. Both animals exhibited noncanceled trials with probability slightly more than $50 \%$. Because we used a stair-casing algorithm to adjust SSD, this departure suggests that both animals tended to speed up, causing a reduction in SSD. We have observed and reported this pattern of behavior before in animals performing the saccadic stop-signal task (Godlove et al., 2009, 2011). Other than a small tendency to speed responses, the data summarized in Table 2 suggest that the monkeys performed the task in a manner consistent with the race model of Logan and Cowan (1984).

\section{Grand average error-ERPs}

Figure 2 shows the saccade-aligned ERPs at electrode Fz collapsed across sessions and monkeys. In both instances, monkeys made saccades to target locations, but different contexts rendered nostop trial responses correct and stop trial responses errant. Compared with the correct no-stop ERPs, the errant, noncanceled ERPs show a negativity beginning $\sim 8 \mathrm{~ms}$ after the error and ending $73 \mathrm{~ms}$ later. This ERN reverses from 150 to $215 \mathrm{~ms}$ postresponse, becoming an error-related Pe. Taking into consideration known neural conduction velocity differences between human and macaque nervous systems (Woodman, 2011), the timing of these potentials show a tight correspondence to the time courses of the ERN and Pe observed in humans (Reinhart et al., 2011). 


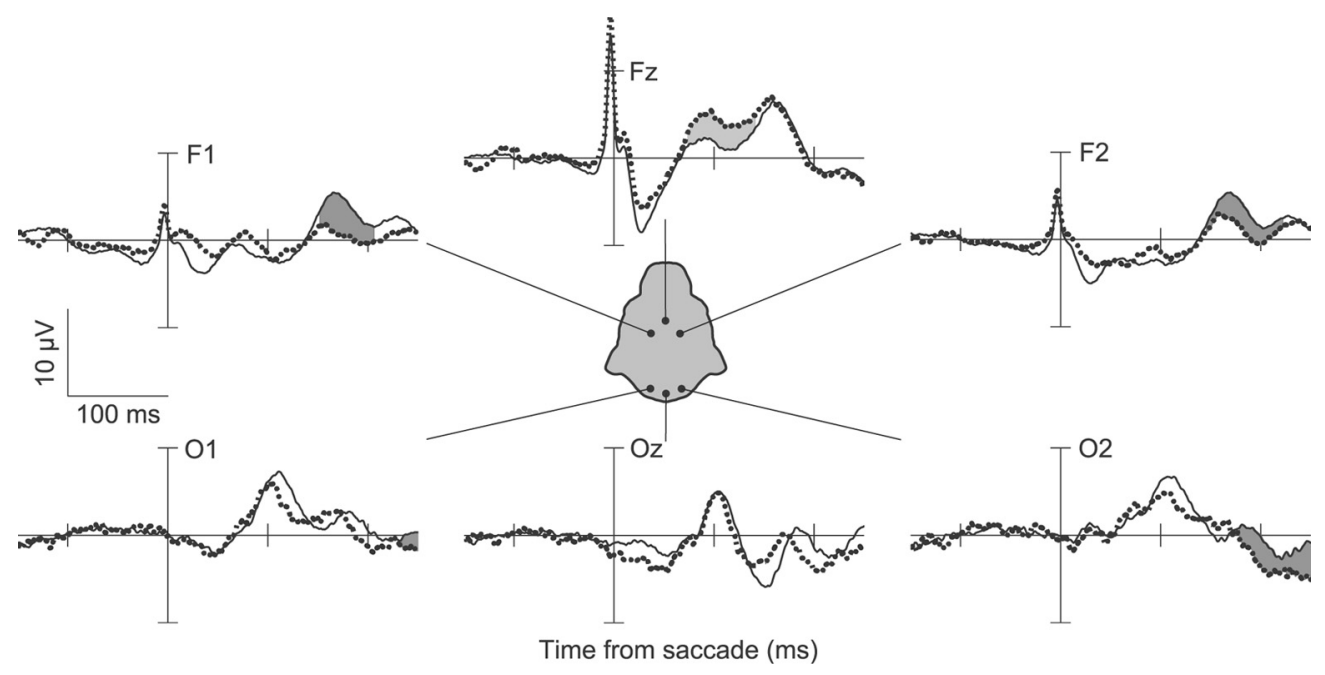

Figure 3. ERPs from monkey F showing the ERN and Pe when errors are committed in the saccadic stop-signal task. The figure uses the same conventions as in Figure 2. Response aligned ERPs from correct no-stop trials and errant noncanceled trials are displayed for multiple electrode locations. On error trials, an early negativity can be observed on electrodes Fz, F1, and F2. This negativity was not of long enough duration to pass significance criteria. A later negativity that does pass significance criteria can also be observed on electrode Fz. Following this, a significant positivity is evident on electrodes F1 and F2. A later significant positivity is also evident on electrodes 01 and 02.

\section{Individual monkey error-ERPs}

Figures 3 and 4 show that a similar pattern of ERN and Pe components was apparent in the frontal medial electrodes of each monkey. In monkey $\mathrm{F}$, the observed ERN was maximal at electrode Fz, $97 \mathrm{~ms}$ after the response, and the Pe was maximal at electrodes F1 and F2 at 170 and 176 ms after the errant saccade, respectively. Monkey Y was implanted with a denser electrode array. This monkey showed a maximal ERN deflection at electrode $\mathrm{FCz}, 64 \mathrm{~ms}$ after the saccade, and a maximal Pe deflection at electrode Fz, 188 ms after the saccade.

\section{Current density model}

The dense electrode array of monkey Y enabled us to investigate the spatial distribution of error-related components in more detail. We calculated current density distributions with the SWARM algorithm using the anatomical MRI from monkey Y. This method takes into account individual skull and brain morphology. Figure 5 shows the results. The current distribution contributing to the ERN explains $84 \%$ of the variance; while that contributing to the Pe explains $86 \%$ of the variance. The current density maps show that the ERN has a broad frontocentral distribution while the Pe has a more focal frontal distribution. The distribution of current sources extended onto medial frontal cortex for both the ERN and the Pe (Fig. 6). These results are strikingly similar those obtained from humans performing the same task (Reinhart et al., 2011).

Because the stop-signal was only presented on trials in which errors were committed, our ERN and Pe results include a contribution from visually evoked ERPs elicited by the stop-signal. We addressed the contribution of this potential confound by comparing current density distributions of canceled and noncanceled trial ERPs during the same time periods relative to the stop-signal (Fig. 5C). On these trials, the monkey held gaze at central fixation for at least $1800 \mathrm{~ms}$ following stop-signal presentation. Therefore, the current distribution on canceled trials reveals the contribution of stimulus-related ERPs to the error-related ERPs. No significant current densities were observed over medial frontal cortex during the ERN epoch when saccades were correctly canceled. Instead, significant effects were restricted to occipital and parietal regions. These results show that the ERN and Pe we ob- served are not sensory artifacts associated with stop-signal presentation.

\section{Error-ERPs, RT adjustments, and response conflict}

Some studies have suggested that error-ERP magnitudes are correlated with performance adjustments such as posterror slowing (Gehring et al., 1993; Nieuwenhuis et al., 2001; RodriguezFornells et al., 2002; Kerns et al., 2004; Debener et al., 2005; Holroyd et al., 2005; Klein et al., 2007; Ladouceur et al., 2007; West and Travers, 2008; Huster et al., 2011; but see Gehring and Fencsik, 2001; Hajcak et al., 2003; Núñez Castellar et al., 2010). To test for these effects and relate our ERP data to intracranial local-field potentials recorded in the SEF and anterior cingulate cortex (ACC) during this task (Emeric et al., 2008, 2010), we examined the relationship between error-related ERPs and posterror RT adjustments, as described above. Figure $7 A$ illustrates this analysis for a sample session. Neither ERN amplitude nor Pe amplitude were significantly correlated with $\Delta \mathrm{RT}$ in this session. Figure $7, B$ and $C$, displays distributions of $\rho$ values collapsed across all sessions. Neither of these distributions deviated significantly from zero (ERN: $t_{(14)}=0.68, p=0.51$; Pe: $t_{(14)}=-1.67, p=0.12$ ).

Because raw EEG contains a great deal of variability, we also averaged the ERPs using a median split based on $\Delta \mathrm{RT}$ and measured amplitudes during the windows centered on the peak ERN and Pe. Figure $8 \mathrm{~A}$ displays mean ERN amplitude for the fastest and slowest $\Delta \mathrm{RT}$ trials separately for each monkey and averaged across both monkeys. Figure $8 B$ displays the same relationship between Pe amplitude and $\Delta \mathrm{RT}$. Neither monkey showed significant differences in ERN amplitude (monkey F: $t_{(18)}=-0.18$, $p=0.86$; monkey $\mathrm{Y}: t_{(8)}=-1.17, p=0.28$; grand: $t_{(28)}=-0.71$, $p=0.48$ ) or in Pe amplitude as a function of $\Delta \mathrm{RT}$ (monkey F: $t_{(18)}=-0.06, p=0.96$; monkey $\mathrm{Y}: t_{(8)}=-1.47, p=0.18$; grand: $\left.t_{(28)}=-1.07, p=0.29\right)$.

An influential theory posits that the ERN is produced by neural processing of response conflict (Botvinick et al., 2001; Yeung et al., 2004). The occurrence of response conflict is not restricted to error trials only, but is hypothesized to occur with varying timing and magnitude on all trial types (Yeung et al., 2004). In the stop-signal task, subjects must choose between committing responses and canceling them. Thus, in the saccadic stop-signal 
context, response conflict is engendered when subjects must choose between producing saccades and maintaining fixation. Distinct neural populations are active in the superior colliculus (SC) and frontal eye field (FEF) when saccades are produced or fixation is maintained. We and others have classified these neurons as movement cells and fixation cells (Bruce and Goldberg, 1985; Munoz and Wurtz, 1993; Hanes et al., 1998), although alternate classifications have been proposed (Hafed et al., 2009). Movement and fixation cells in the SC (Paré and Hanes, 2003) and FEF (Hanes et al., 1998) are briefly coactive on canceled trials around the time that saccade cancelation occurs (SSRT). This coactivation is largest when saccades are successfully canceled under conditions in which they are likely to occur. Similar coactivation of movement and fixation cells has not been observed on errant noncanceled trials. In sum, the probability of successfully canceling action that varies as a function of SSD yields a reliable proxy measurement of neural response conflict on canceled trials in the saccadic stop-signal task. Using this metric, it has been shown that response conflict may be reflected in single cell and local field potential (LFP) signals of SEF (Stuphorn et al., 2000; Emeric et al., 2010). But this conflict signal has not been observed in the single-cell and LFP responses of ACC (Ito et al., 2003; Emeric et al., 2008).

We tested for conflict-related activity in ERPs aligned to SSRT on canceled trials using the method of Stuphorn et al. (2000). The mean voltage differences between canceled and no-stop trials in the -50 to $+100 \mathrm{~ms}$ time window around SSRT at each SSD are plotted in Figure 9 as a function of both SSD and the probability of failing to cancel. These voltage differences did not show significant correlations with either SSD $\left(\rho_{(35)}=-0.08, p=\right.$ 0.63 ) or the probability of committing er-

rant noncanceled responses $\left(\rho_{(35)}=0.27, p=0.11\right)$.

\section{Control for saccade-related artifacts}

To ensure that the observed error-ERPs were not due to response-related components, we quantified saccade dynamics on no-stop and noncanceled trials. Because we time-locked our ERPs to response onset, we could rule out the confounding effects of RT differences between trial types. However, if the task-related saccade amplitude or duration differed between correct and errant saccades, it could lead to differences in the electromyogram or the corneoretinal potential between trial types (Luck, 2005; Godlove et al., 2011) and these artifacts could be interpreted as performance-monitoring ERPs (Godlove, 2010).

Figure 10 summarizes saccade amplitude and duration separated by monkey, target, and trial type. We performed three-way

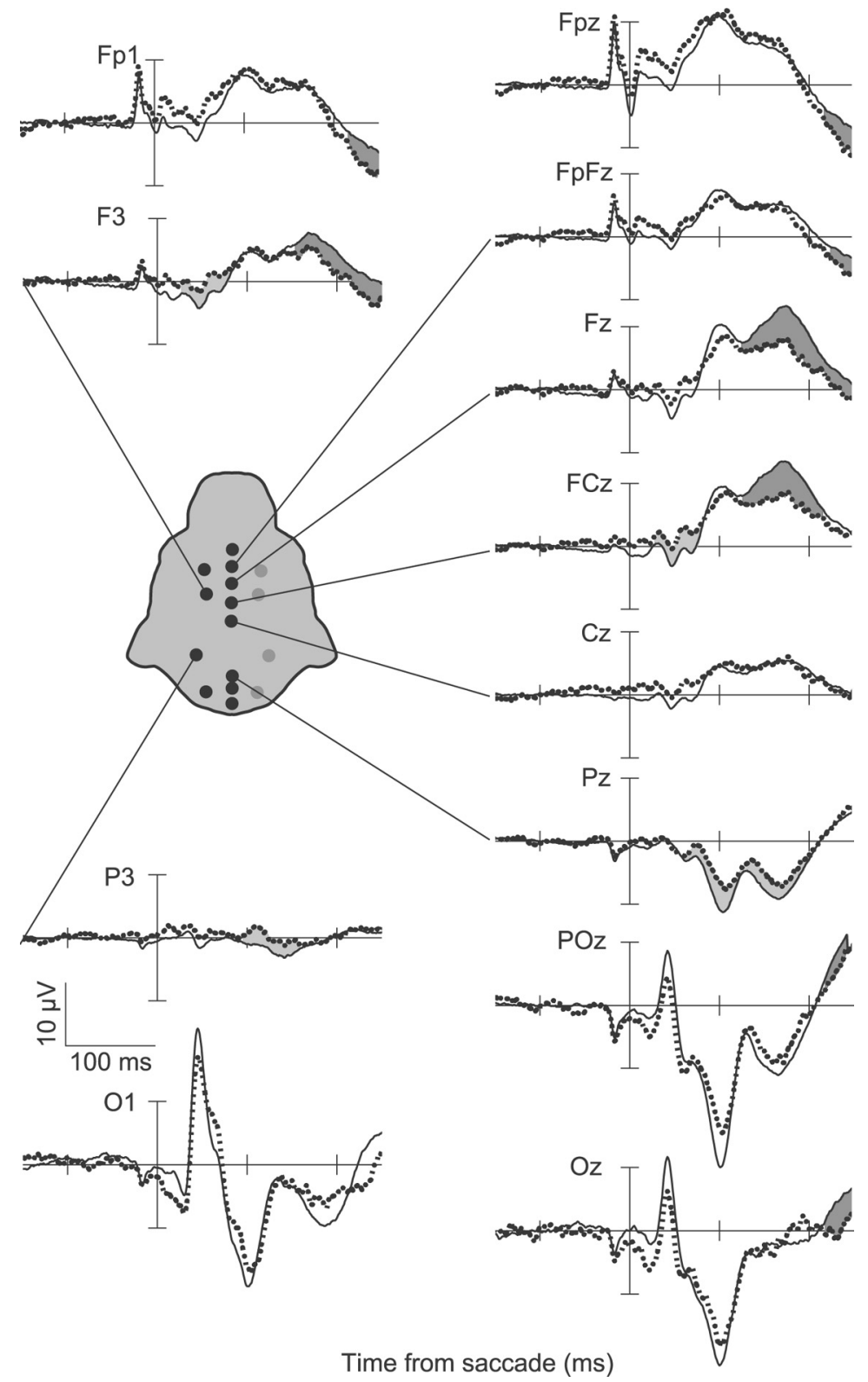

Figure 4. ERPs from monkey $Y$ showing the ERN and Pe when errors are committed in the saccadic stop-signal task with the same conventions as in Figure 2. Response aligned ERPs from correct no-stop trials and errant noncanceled trials are displayed for multiple electrode locations. On error trials, a significant negativity can be observed on electrodes $\mathrm{FC}$ and $\mathrm{F} 3$, and a later negativity can also be observed on electrode Pz. Following this, a significant positivity can be observed on the majority of electrodes. This positivity is earliest and highest in amplitude at frontal medial electrode sites.

ANOVAs to test the hypotheses that saccade amplitude, velocity, or duration differed between monkey, target, or trial type. Saccade velocity and duration both differed significantly between monkeys. Monkey $\mathrm{F}$ made saccades with higher peak velocity $\left(F_{(1,52)}=12.37, p<0.001\right)$ and longer duration $\left(F_{(1,52)}=5.22\right.$, $p<0.05)$ than monkey Y. This means that monkey $\mathrm{F}$ also tended to make slightly larger amplitude saccades, although this comparison did not reach statistical significance. Saccade dynamics differed modestly between targets for both monkeys. When monkeys made saccades to the rightward target, they tended to be of larger amplitude $\left(F_{(1,52)}=27.36, p<0.001\right)$, higher peak velocity $\left(F_{(1,52)}=71.19, p<0.001\right)$, and shorter duration $\left(F_{(1,52)}\right.$ $=28.66, p<0.001)$. This may be an artifact induced by the monocular eye tracking procedures we used. Because we only tracked the right eye of each monkey, saccade traces to the right 
A
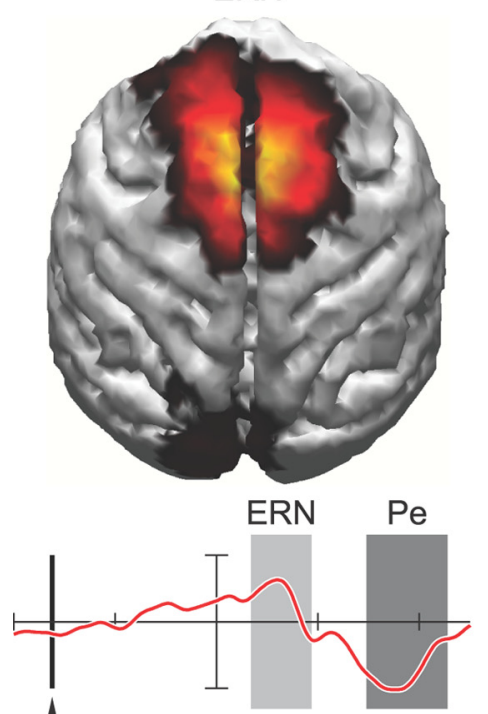

Time from saccade (ms)

Median stop-signal time $(-162 \mathrm{~ms})$

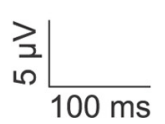

B

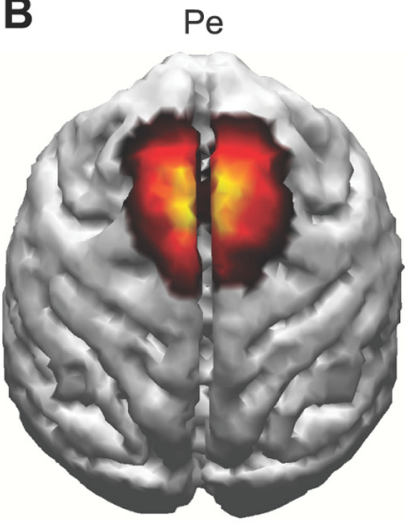

C
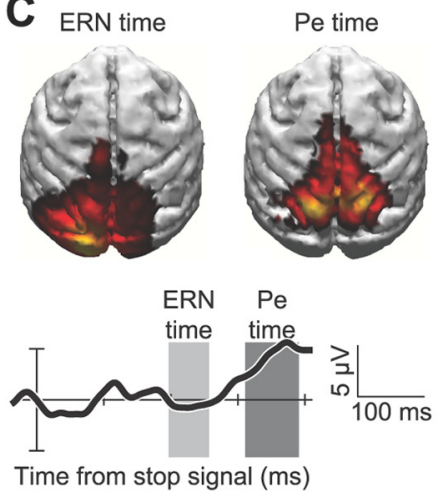

Figure 5. $\quad \boldsymbol{A}-\boldsymbol{C}$, Current density distribution for $\operatorname{ERN}(\boldsymbol{A}), \operatorname{Pe}(\boldsymbol{B})$, and visual response to stop signal (C). Current density estimates are projected onto MRI reconstruction from the same monkey. Warmer colors indicate greater density of current flow according to the scale for the ERN on the left side of the key and the Pe on the right side of the key. Error minus correct difference wave (red) and response to stop signal on correct canceled trials (black) are shown with temporal windows measured for each component. Vertical line shows median stop signal presentation time relative to saccade initiation.

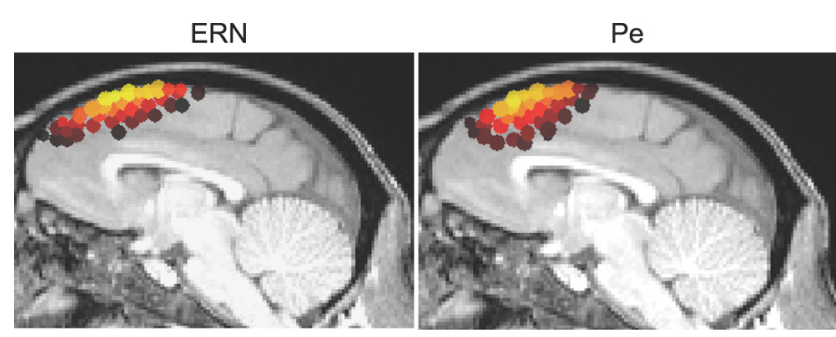

Figure 6. Sagittal view of current density spatial distributions for ERN and Pe. Conventions are as in Figure 5.

target reflected abduction of the tracked eye while saccade traces to the left target reflected adduction of the tracked eye. To ensure that target bias did not affect ERP component analysis, approximately equal numbers of trials were included in each ERP for each trial type (see Materials and Methods, above). A marginally significant effect was noted for saccade velocity between correct and errant trials. Both monkeys tended to make higher velocity saccades on error trials than correct trials $\left(F_{(1,52)}=4.17, p=\right.$ $0.05)$. However, velocity effects could not explain the different ERPs observed on error and correct trials unless saccadic endpoints also differed, shifting the corneoretinal potential to a greater degree on one type of trial relative to the other, or saccade duration differed smearing temporal saccade artifacts in one condition more than another. Critically, neither saccade amplitude $\left(F_{(1,52)}=1.62, p=0.2\right)$ nor saccade duration $\left(F_{(1,52)}=1.17, p=\right.$

0.3) differed significantly between correct and errant trials. Therefore, no difference in correct and error saccade dynamics could explain the error-ERP effects.

\section{Discussion}

We have shown that during a saccadic stopsignal task, macaques exhibit ERN and Pe components homologous to those recorded from humans. The precise timing and distributions of these error-related ERPs might initially appear to differ from those reported in humans using manual responses (for review, see Gehring et al., 2011). However, parallel experiments with humans show that the anterior distribution of monkey error-ERPs recorded during the saccadic stop-signal task is virtually identical to that found in humans (Reinhart et al., 2011).

In agreement with our parallel experiments with human subjects (Reinhart et al., 2011), we observed no single-trial correlations between ERN or Pe amplitude and posterror RT adjustments. Reported relationships between error-ERPs and posterror RT adjustments vary across the literature. Although some report such correlations (Gehring et al., 1993; Nieuwenhuis et al., 2001; Rodriguez-Fornells et al., 2002; Kerns et al., 2004; Debener et al., 2005; Holroyd et al., 2005; Klein et al., 2007; Ladouceur et al., 2007; West and Travers, 2008; Huster et al., 2011), others report no or contradictory evidence (Gehring and Fencsik, 2001; Hajcak et al., 2003; Núñez Castellar et al., 2010). Additionally, posterror slowing is not consistently observed in the stop-signal task (Emeric et al., 2007; Nelson et al., 2010; Bissett and Logan, 2011). Single-trial EEG has variability that is approximately an order of magnitude higher than ERPs (Luck, 2005), so we also analyzed the ERP data using a median split of posterror RT. Even with reduced variability due to averaging, we did not observe consistent error-ERP fluctuations predicting posterror RT adjustments. In addition, we did not observe conflict-related modulation of ERPs. These findings agree with those from our parallel study with humans performing the same task, but challenge the view that error-ERPs reflect the activity of a general conflict monitoring system (Yeung et al., 2004).

We previously reported error-related LFPs recorded in ACC and SEF during the saccadic stop-signal task (Emeric et al., 2008, 2010). It is tempting to speculate that these LFPs give rise to the error-ERPs recorded at the surface, but several observations complicate this interpretation. First, error-related LFPs and ERPs differ in their relationships to behavior. Error-related LFP amplitude recorded from SEF is correlated with posterror RT adjustments. And SEF LFPs also exhibit a negative potential during periods of increased response conflict (Emeric et al., 2010). In contrast, LFPs recorded in ACC exhibit a positivity with increased response conflict (Emeric et al., 2008). We observed no such correlations in surface ERPs. These conflicting results from recording inside and outside the brain support the assumption that ERP signals arise from the summation of LFPs generated broadly throughout the brain (Luck, 2005; Nunez and Sriniva- 

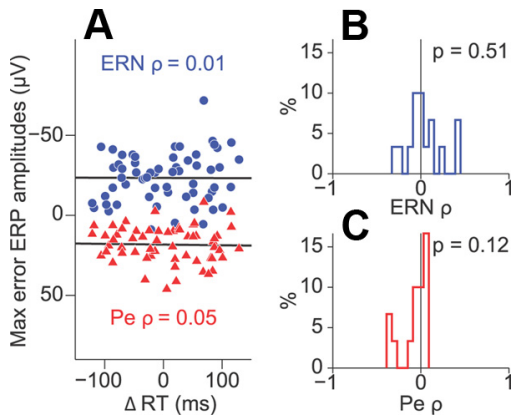

Figure 7. Single-trial test for correlations between ERN/Pe amplitude and posterror RT adjustments. $A$, Correlations between maximum ERN/Pe amplitude and $\Delta R T$ (RT on no-stop trial $n+1$ minus RT on noncanceled trial $n$ ) for a representative session. Neither the correlation between maximum ERN amplitude and $\Delta R T$ nor the correlation between maximum Pe amplitude and $\Delta R T$ reached significance. $\boldsymbol{B}$, Distribution of correlation coefficients ( $\rho$ s) between maximum ERN amplitude and $\Delta R T$ across all sessions. $C$, Distribution of $\rho$ s between maximum Pe amplitude and $\Delta R T$ across all sessions.

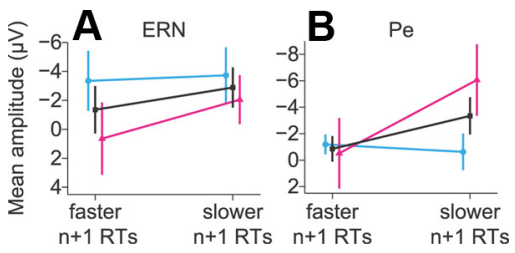

Figure 8. Median split ERP test for relationship between ERN/Pe amplitude and $\Delta R T$. $\boldsymbol{A}$, Mean amplitude of the ERN followed by no-stop trials with faster RTs (left) or trials with slower RTs (right) for monkey $F$ (cyan), monkey $Y$ (magenta), and grand average (black). Error bars display SEM. $\boldsymbol{B}$, Mean Pe amplitude data presented in same format as in $\boldsymbol{A}$. No comparisons reached statistical significance.

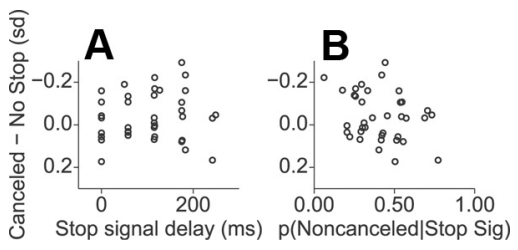

Figure 9. Test for conflict-related activity in canceled ERP data. $\boldsymbol{A}$, Normalized mean voltage difference between canceled trials and latency matched no-stop trials in the $-50-100 \mathrm{~ms}$ time window around SSRT plotted against SSD. B, Same voltage data as in $A$ plotted against the probability of committing an errant noncanceled saccade at each SSD. Significant correlations were not observed in either case (see Results).

san, 2006). Thus, surface ERPs cannot be fully explained by LFPs in SEF or ACC. Second, timing differences between the ERPs and LFPs are obvious (Fig. 11). The onset of the ERN and Pe on the surface precede intracranial LFP onsets. One possible explanation for these results is that subjects may show individual differences in timing of error-ERP onset, or that timing may change as subjects gain experience. Simultaneous ERP and LFP recordings must be performed to test these explanations.

The observation of monkey error-ERPs will allow for their detailed neurophysiological characterization. Single units in ACC (Shima and Tanji, 1998; Ito et al., 2003; Amiez et al., 2005) and SEF (Stuphorn et al., 2000) are modulated when monkeys commit errors. Neurons in ACC modulate when monkeys switch responses after errors (Johnston et al., 2007; Quilodran et al., 2008). SEF neurons also show activity that may bias performance toward rewarding responses (Coe et al., 2002; Stuphorn et al., 2010), and stimulation of SEF improves saccadic stop-signal per-

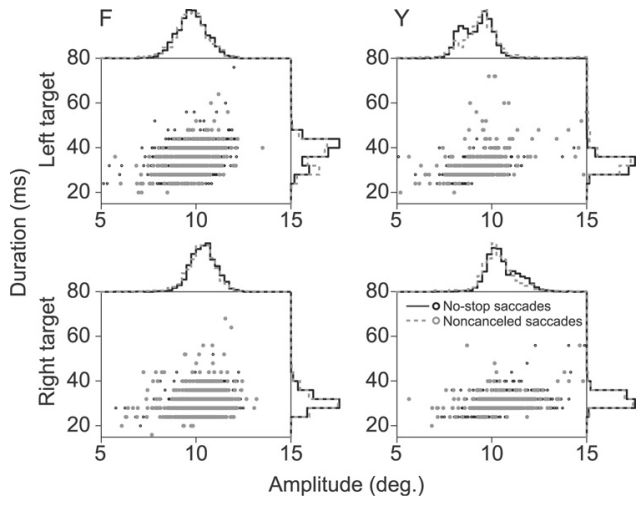

Figure 10. Saccade dynamics between conditions. Scatter plots display saccade amplitude versus duration across all sessions and both monkeys. Histograms display associated probability densities for each measurement. Bin widths are $4 \mathrm{~ms}$ for saccade duration distributions and $0.25^{\circ}$ for amplitude distributions. Black dots and solid lines represent saccades on no-stop trials. Gray dots and dashed lines represent saccades on noncanceled trials. Rows separate data by target. Columns separate data by monkey. Although saccade dynamics were found to differ between monkeys and targets, neither saccade amplitude nor saccade duration were found to differ significantly between trial types. These findings indicate that the observed monkey ERN and $P e$ are not caused by differences in saccade dynamics between conditions.
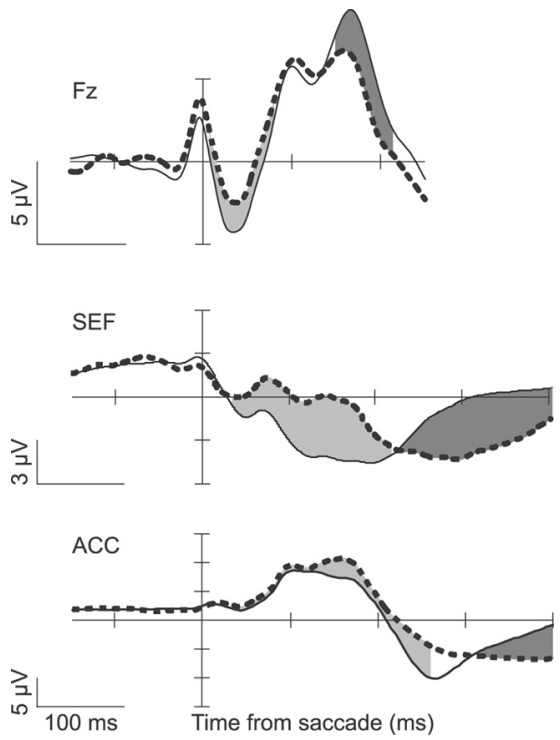

Figure 11. Comparison of error-ERPs to error-related LFPs. Error-ERPs from the current study (top) are plotted alongside error-related LFPs recorded in SEF (middle) (Emeric et al., 2010) and ACC (bottom) (Emeric et al., 2010) for amplitude and timing comparisons. Conventions are as in Figure 2.

formance (Stuphorn and Schall, 2006). Despite these results, some have wondered whether intracranial recordings in monkeys are generated by the same error-monitoring processes reflected in human ERPs (Cole et al., 2009, 2010; but see Schall and Emeric, 2010). The finding of monkey error-ERPs thus bridges a gap between human and monkey studies of executive control.

Several issues require clarification. First, the precise neuroanatomical loci of error-ERPs have not been described. Second, the neurophysiological events that give rise to the ERN and Pe remain obscure. Third, several models have been proposed to explain the relationship of error-ERPs to performance monitoring generally, but the neural plausibility of these theories remains speculative. Neurophysiological recordings with nonhuman primates can shed much needed light on these questions. For the 
remainder of the Discussion, we will consider each of these issues in turn.

\section{What are the anatomical sources of error-ERPs?}

Dipole source modeling efforts and fMRI results suggest a central role for the dorsal ACC (Dehaene et al., 1994; Carter et al., 1998; Holroyd et al., 1998; for review, see Taylor et al., 2007). However, it is well known that dipole source techniques rely on underconstrained solutions to the inverse problem of ERP localization (Helmholtz, 1853; Luck, 2005). Moreover, the link between electrophysiology and hemodynamic regulation is poorly understood (Logothetis and Wandell, 2004). Evidence indicates that other areas may play an important role in producing error-ERPs (for review, see Gehring et al., 2011). In addition to the studies with monkeys described above, researchers have implicated the supplementary motor area and rostral ACC as potential substrates for error-ERPs (Dehaene et al., 1994; Kiehl et al., 2000; Menon et al., 2001; Luu et al., 2003). Also, intracranial recordings in patients show error-related activity in multiple cortical areas beyond medial frontal cortex (Brázdil et al., 2002; Halgren et al., 2002). An animal model will be a great asset in the search for definitive neural generators.

\section{What is the physiology underlying observed ERN and Pe?}

The idea that mesocortical dopaminergic (DAergic) signaling produces the ERN has received substantial interest (Holroyd and Coles, 2002). However, relatively few researchers have experimentally manipulated DAergic signaling pathways (for review, see Jocham and Ullsperger, 2009). Because studies using the ERN have been performed in humans, invasive neuroscientific techniques have been impractical. This is discouraging, since the DA hypothesis is rooted in classic neurophysiological studies using monkeys (Schultz et al., 1997; Schultz, 1998; Redgrave et al., 1999a,b). Although DA has received the most attention, several other neurotransmitters may also play a role in generating errorERPs. These include norepinephrine (Riba et al., 2005b), serotonin (Fallgatter et al., 2004), and GABA (Johannes et al., 2001; de Bruijn et al., 2004; Riba et al., 2005a). The discovery of monkey error-ERPs will open new avenues for research on the neurochemical and neurophysiological events underlying these components. Now, tools such as selective agonist and antagonist microinjections can be combined with surface electrode recordings to determine the contributions of various neurotransmitters and cell populations to error-ERPs.

\section{What is the relationship between error-ERPs and performance monitoring?}

The relationship between error-ERPs and performance monitoring is unclear. They were first thought to reflect neural processing of mismatch between committed and intended responses (Falkenstein et al., 1990; Gehring et al., 1993; Coles et al., 2001). This view has several drawbacks. For instance, if some area has access to a representation of the intended response, why was a different response executed (but see Murthy et al., 2007, 2009)? Other theories allow performance monitoring to proceed without a priori knowledge of future outcomes. Several of these have been expressed as computational models that frame precise hypotheses (Botvinick et al., 2001; Holroyd and Coles, 2002; Yeung et al., 2004; Brown and Braver, 2005). The most influential computational models cannot be resolved using behavioral data alone. For instance, a major obstacle in testing the conflict monitoring theory arises from an inability to measure response conflict directly (Gehring et al., 2011). Similarly, reinforcement-learning theories
(Holroyd and Coles, 2002; Brown and Braver, 2005) have proven difficult to test using behavioral measures alone. However, specific assumptions of these models can be tested with neurophysiological measures in an animal model of error-ERP.

\section{References}

Amiez C, Joseph JP, Procyk E (2005) Anterior cingulate error-related activity is modulated by predicted reward. Eur J Neurosci 21:3447-3452.

Bissett PG, Logan GD (2011) Balancing cognitive demands: control adjustments in the stop-signal paradigm. J Exp Psychol Learn Mem Cogn 37:392-404.

Botvinick MM, Braver TS, Barch DM, Carter CS, Cohen JD (2001) Conflict monitoring and cognitive control. Psychol Rev 108:624-652.

Brázdil M, Roman R, Falkenstein M, Daniel P, Jurák P, Rektor I (2002) Error processing-evidence from intracerebral ERP recordings. Exp Brain Res 146:460-466.

Brown JW, Braver TS (2005) Learned predictions of error likelihood in the anterior cingulate cortex. Science 307:1118-1121.

Bruce CJ, Goldberg ME (1985) Primate frontal eye fields. I. Single neurons discharging before saccades. J Neurophysiol 53:603-635.

Carter CS, Braver TS, Barch DM, Botvinick MM, Noll D, Cohen JD (1998) Anterior cingulate cortex, error detection, and the online monitoring of performance. Science 280:747-749.

Coe B, Tomihara K, Matsuzawa M, Hikosaka O (2002) Visual and anticipatory bias in three cortical eye fields of the monkey during an adaptive decision-making task. J Neurosci 22:5081-5090.

Cole MW, Yeung N, Freiwald WA, Botvinick M (2009) Cingulate cortex: diverging data from humans and monkeys. Trends Neurosci 32:566-574.

Cole MW, Yeung N, Freiwald WA, Botvinick M (2010) Conflict over cingulate cortex: between-species differences in cingulate may support enhanced cognitive flexibility in humans. Brain Behav Evol 75:239-240.

Coles MG, Scheffers MK, Holroyd CB (2001) Why is there an ERN/Ne on correct trials? Response representations, stimulus-related components, and the theory of error-processing. Biol Psychol 56:173-189.

Dale AM, Sereno MI (1993) Improved localization of cortical activity by combining EEG and MEG with MRI cortical surface reconstruction: a linear-approach. J Cogn Neurosci 5:162-176.

Debener S, Ullsperger M, Fiehler K, von Cramon DY, Engel AK (2005) Monitoring error processing by means of simultaneous EEG/fMRI recordings. II. Single-trial independent component analysis of the errorrelated negativity (ERN). J Psychophysiol 19:111.

de Bruijn ERA, Hulstijn W, Verkes RJ, Ruigt GSF, Sabbe BG (2004) Druginduced stimulation and suppression of action monitoring in healthy volunteers. Psychopharmacology (Berl) 177:151-160.

Dehaene S, Posner MI, Tucker DM (1994) Localization of a neural system for error-detection and compensation. Psychol Sci 5:303-305.

Emeric EE, Brown JW, Boucher L, Carpenter RH, Hanes DP, Harris R, Logan GD, Mashru RN, Paré M, Pouget P, Stuphorn V, Taylor TL, Schall JD (2007) Influence of history on saccade countermanding performance in humans and macaque monkeys. Vision Res 47:35-49.

Emeric EE, Brown JW, Leslie M, Pouget P, Stuphorn V, Schall JD (2008) Performance monitoring local field potentials in the medial frontal cortex of primates: anterior cingulate cortex. J Neurophysiol 99:759-772.

Emeric EE, Leslie M, Pouget P, Schall JD (2010) Performance monitoring local field potentials in the medial frontal cortex of primates: supplementary eye field. J Neurophysiol 104:1523-1537.

Endrass T, Franke C, Kathmann N (2005) Error awareness in a saccade countermanding task. J Psychophysiol 19:275-280.

Falkenstein M, Hohnsbein J, Blanke L (1990) Effects of errors in choice reaction tasks on the ERP under focused and divided attention. In: Psychophysiological brain research (Brunia CH, Gaillard AW, Kok A, eds), pp 192-195. Tilburg, The Netherlands: Tilburg UP.

Falkenstein M, Hoormann J, Christ S, Hohnsbein J (2000) ERP components on reaction errors and their functional significance: a tutorial. Biol Psychol 51:87-107.

Fallgatter AJ, Herrmann MJ, Roemmler J, Ehlis AC, Wagener A, Heidrich A, Ortega G, Zeng Y, Lesch KP (2004) Allelic variation of serotonin transporter function modulates the brain electrical response for error processing. Neuropsychopharmacology 29:1506-1511.

Garr AK, Emeric EE, Schall JD (2008) Extracranial error-related potential in macaque monkeys during saccade countermanding. Soc Neurosci Abstr $34: 770.10$. 
Gehring WJ, Fencsik DE (2001) Functions of the medial frontal cortex in the processing of conflict and errors. J Neurosci 21:9430-9437.

Gehring WJ, Goss B, Coles MG, Meyer DE, Donchin E (1993) A neural system for error-detection and compensation. Psychol Sci 4:385-390.

Gehring WJ, Liu Y, Orr JM, Carp J (2011) The error-related negativity (ERN/Ne). In: Oxford handbook of event-related potential components (Luck SJ, Kappenman E, eds), pp 231-291. New York: Oxford UP.

Godlove DC (2010) Eye movement artifact may account for putative frontal feedback-related potentials in nonhuman primates. J Neurosci 30:41874189.

Godlove DC, Emeric EE, Boucher L, Schall JD (2009) Express saccade production in a stop signal task. Soc Neurosci Abst 35:71.6.

Godlove DC, Garr AK, Woodman GF, Schall JD (2011) Measurement of the extraocular spike potential during saccade countermanding. J Neurophysiol 106:104-114.

Hafed ZM, Goffart L, Krauzlis RJ (2009) A neural mechanism for microsaccade generation in the primate superior colliculus. Science 323:940-943.

Hajcak G, McDonald N, Simons RF (2003) To err is autonomic: errorrelated brain potentials, ANS activity, and post-error compensatory behavior. Psychophysiology 40:895-903.

Halgren E, Boujon C, Clarke J, Wang C, Chauvel P (2002) Rapid distributed fronto-parieto-occipital processing stages during working memory in humans. Cereb Cortex 12:710-728.

Hanes DP, Schall JD (1995) Countermanding saccades in macaque. Vis Neurosci 12:929-937.

Hanes DP, Patterson WF 2nd, Schall JD (1998) Role of frontal eye fields in countermanding saccades: visual, movement, and fixation activity. J Neurophysiol 79:817-834.

Helmholtz H (1853) Ueber einige gesetze der verteilung elektrischer ströme in körperlichen leitern mit anwendung auf die thierisch-elektrischen versuche. Psychophysiology 17:259-273.

Hikosaka O, Isoda M (2010) Switching from automatic to controlled behavior: cortico-basal ganglia mechanisms. Trends Cogn Sci 14:154-161.

Holroyd CB, Coles MG (2002) The neural basis of human error processing: reinforcement learning, dopamine, and the error-related negativity. Psychol Rev 109:679-709.

Holroyd CB, Dien J, Coles MG (1998) Error-related scalp potentials elicited by hand and foot movements: evidence for an output-independent errorprocessing system in humans. Neurosci Lett 242:65-68.

Holroyd CB, Yeung N, Coles MG, Cohen JD (2005) A mechanism for error detection in speeded response time tasks. J Exp Psychol Gen 134:163-191.

Huster RJ, Eichele T, Enriquez-Geppert S, Wollbrink A, Kugel H, Konrad C, Pantev C (2011) Multimodal imaging of functional networks and eventrelated potentials in performance monitoring. Neuroimage 56:1588-1597.

Ito S, Stuphorn V, Brown JW, Schall JD (2003) Performance monitoring by the anterior cingulate cortex during saccade countermanding. Science 302:120-122.

Jocham G, Ullsperger M (2009) Neuropharmacology of performance monitoring. Neurosci Biobehav Rev 33:48-60.

Johannes S, Wieringa BM, Nager W, Dengler R, Munte TF (2001) Oxazepam alters action monitoring. Psychopharmacology (Berl) 155:100-106.

Johnston K, Levin HM, Koval MJ, Everling S (2007) Top-down controlsignal dynamics in anterior cingulate and prefrontal cortex neurons following task switching. Neuron 53:453-462.

Kerns JG, Cohen JD, MacDonald AW 3rd, Cho RY, Stenger VA, Carter CS (2004) Anterior cingulate conflict monitoring and adjustments in control. Science 303:1023-1026.

Kiehl KA, Liddle PF, Hopfinger JB (2000) Error processing and the rostral anterior cingulate: an event-related fMRI study. Psychophysiology $37: 216-223$.

Klein TA, Endrass T, Kathmann N, Neumann J, von Cramon DY, Ullsperger M (2007) Neural correlates of error awareness. Neuroimage 34:1774-1781.

Krämer UM, Cunillera T, Càmara E, Marco-Pallarés J, Cucurell D, Nager W, Bauer P, Schüle R, Schöls L, Rodriguez-Fornells A, Münte TF (2007) The impact of catechol-O-methyltransferase and dopamine D4 receptor genotypes on neurophysiological markers of performance monitoring. J Neurosci 27:14190-14198.

Ladouceur CD, Dahl RE, Carter CS (2007) Development of action monitoring through adolescence into adulthood: ERP and source localization. Dev Sci 10:874-891.
Liotti M, Pliszka SR, Perez R, Kothmann D, Woldorff MG (2005) Abnormal brain activity related to performance monitoring and error detection in children with ADHD. Cortex 41:377-388.

Logan GD, Cowan WB (1984) On the ability to inhibit thought and action: a theory of an act of control. Psychol Rev 91:295-327.

Logothetis NK, Wandell BA (2004) Interpreting the BOLD signal. Annu Rev Physiol 66:735-769.

Luck SJ (2005) An introduction to the event-related potential technique. Cambridge, MA: MIT.

Luu P, Tucker DM, Derryberry D, Reed M, Poulsen C (2003) Electrophysiological responses to errors and feedback in the process of action regulation. Psychol Sci 14:47-53.

Menon V, Adleman NE, White CD, Glover GH, Reiss AL (2001) Errorrelated brain activation during a Go/NoGo response inhibition task. Hum Brain Mapp 12:131-143.

Munoz DP, Wurtz RH (1993) Fixation cells in monkey superior colliculus. I. Characteristics of cell discharge. J Neurophysiol 70:559-575.

Murthy A, Ray S, Shorter SM, Priddy EG, Schall JD, Thompson KG (2007) Frontal eye field contributions to rapid corrective saccades. J Neurophysiol 97:1457-1469.

Murthy A, Ray S, Shorter SM, Schall JD, Thompson KG (2009) Neural control of visual search by frontal eye field: effects of unexpected target displacement on visual selection and saccade preparation. J Neurophysiol 101:2485-2506.

Nelson MJ, Boucher L, Logan GD, Palmeri TJ, Schall JD (2010) Nonindependent and nonstationary response times in stopping and stepping saccade tasks. Atten Percept Psychophys 72:1913-1929.

Nieuwenhuis S, Ridderinkhof KR, Blom J, Band GP, Kok A (2001) Errorrelated brain potentials are differentially related to awareness of response errors: evidence from an antisaccade task. Psychophysiology 38:752-760.

Núñez Castellar E, Kühn S, Fias W, Notebaert W (2010) Outcome expectancy and not accuracy determines posterror slowing: ERP support. Cogn Affect Behav Neurosci 10:270-278.

Nunez PL, Srinivasan R (2006) Electric fields of the brain: the neurophysics of EEG, 2nd Edition. Oxford: Oxford UP.

Paré M, Hanes DP (2003) Controlled movement processing: superior colliculus activity associated with countermanded saccades. J Neurosci 23:6480-6489.

Pascual-Marqui RD (2002) Standardized low-resolution brain electromagnetic tomography (sLORETA): technical details. Methods Find Exp Clin Pharmacol 24:5-12.

Passingham RE, Bengtsson SL, Lau HC (2010) Medial frontal cortex: from self-generated action to reflection on one's own performance. Trends Cogn Sci 14:16-21.

Paus T (2001) Primate anterior cingulate cortex: where motor control, drive and cognition interface. Nat Rev Neurosci 2:417-424.

Quilodran R, Rothé M, Procyk E (2008) Behavioral shifts and action valuation in the anterior cingulate cortex. Neuron 57:314-325.

Redgrave P, Prescott TJ, Gurney K (1999a) The basal ganglia: a vertebrate solution to the selection problem? Neuroscience 89:1009-1023.

Redgrave P, Prescott TJ, Gurney K (1999b) Is the short-latency dopamine response too short to signal reward error? Trends Neurosci 22:146-151.

Reinhart RM, Carlisle NB, Kang MS, Woodman GF (2011) Error processing during saccade and manual stop signal task in humans: timing and source estimation. Soc Neurosci Abstr 37:930.1.

Riba J, Rodríguez-Fornells A, Münte TF, Barbanoj MJ (2005a) A neurophysiological study of the detrimental effects of alprazolam on human action monitoring. Brain Res Cogn Brain Res 25:554-565.

Riba J, Rodríguez-Fornells A, Morte A, Münte TF, Barbanoj MJ (2005b) Noradrenergic stimulation enhances human action monitoring. J Neurosci $25: 4370-4374$.

Ridderinkhof KR, Ullsperger M, Crone EA, Nieuwenhuis S (2004) The role of the medial frontal cortex in cognitive control. Science 306:443-447.

Rodriguez-Fornells A, Kurzbuch AR, Münte TF (2002) Time course of error detection and correction in humans: neurophysiological evidence. J Neurosci 22:9990-9996.

Schall JD, Boucher L (2007) Executive control of gaze by the frontal lobes. Cogn Affect Behav Neurosci 7:396-412.

Schall JD, Emeric EE (2010) Conflict in cingulate cortex function between humans and macaque monkeys: more apparent than real. Comment on "Cingulate cortex: diverging data from humans and monkeys." Brain Behav Evol 75:237-238. 
Schultz W (1998) Predictive reward signal of dopamine neurons. J Neurophysiol 80:1-27.

Schultz W, Dayan P, Montague PR (1997) A neural substrate of prediction and reward. Science 275:1593-1599.

Shima K, Tanji J (1998) Role for cingulate motor area cells in voluntary movement selection based on reward. Science 282:1335-1338.

Stahl J, Gibbons H (2007) Dynamics of response-conflict monitoring and individual differences in response control and behavioral control: an electrophysiological investigation using a stop-signal task. Clin Neurophysiol 118:581-596.

Stuphorn V, Schall JD (2006) Executive control of countermanding saccades by the supplementary eye field. Nat Neurosci 9:925-931.

Stuphorn V, Taylor TL, Schall JD (2000) Performance monitoring by the supplementary eye field. Nature 408:857-860.

Stuphorn V, Brown JW, Schall JD (2010) Role of supplementary eye field in saccade initiation: executive, not direct, control. J Neurophysiol 103:801-816.

Taylor SF, Stern ER, Gehring WJ (2007) Neural systems for error monitoring: recent findings and theoretical perspectives. Neuroscientist 13:160172.

van Boxtel GJ, van der Molen MW, Jennings JR (2005) Differential involve- ment of the anterior cingulate cortex in performance monitoring during a stop-signal task. J Psychophysiol 19:1-10.

Vocat R, Pourtois G, Vuilleumier P (2008) Unavoidable errors: a spatiotemporal analysis of time-course and neural sources of evoked potentials associated with error processing in a speeded task. Neuropsychologia 46:2545-2555.

Wagner M, Fuchs M, Kastner J (2007) SWARM: sLORETA-weighted accurate minimum norm inverse solutions. Internat Congr Series 1300:185188.

West R, Travers S (2008) Tracking the temporal dynamics of updating cognitive control: an examination of error processing. Cereb Cortex 18:1112-1124.

Woodman GF (2011) Homologues of human event-related potential components in nonhuman primates. In: Oxford handbook of event-related potential components (Luck SJ, Kappenman E, eds), pp 611-625. New York: Oxford UP.

Woodman GF, Kang MS, Rossi AF, Schall JD (2007) Nonhuman primate event-related potentials indexing covert shifts of attention. Proc Natl Acad Sci U S A 104:15111-15116.

Yeung N, Botvinick MM, Cohen JD (2004) The neural basis of error detection: conflict monitoring and the error-related negativity. Psychol Rev 111:931-959. 